\title{
DISTRIBUIÇÃO DE GRUPOS CLONAIS DE LISTERIA MONOCYTOGENES EM CARCAÇAS E NO AMBIENTE DE MATADOUROS FRIGORÍFICOS DE SUÍNOS
}

\author{
Andréia Inês Ferronatto¹, Débora da Cruz Payão Pellegrini ${ }^{1}$, Priscila Guerra1 ${ }^{1}$, Marisa \\ Ribeiro de Itapema Cardoso ${ }^{1}$ \\ 1 UFRGS \\ Correspondência: Marisa Cardoso: mcardoso@ufrgs.br
}

\begin{abstract}
RESUMO: O objetivo deste estudo foi determinar a presença e distribuição de perfis clonais de isolados de Listeria monocytogenes, agrupados após a sorotipificação e macrorestrição de DNA seguida de eletroforese em campo pulsado (PFGE), em carcaças de suínos amostradas em quatro pontos da linha de abate e no ambiente de matadouros frigoríficos. Suabes de superfície foram coletados no ambiente $(n=30)$ e na superfície de carcaças $(n=240)$ após a escaldagem, chamuscamento, evisceração e na entrada da câmara fria, em dois matadouros frigoríficos localizados no sul do Brasil. Dos 270 suabes analisados, 21 (7,7\%) foram positivos para o gênero Listeria, distribuídas nas espécies, L. innocua (10), L. monocytogenes (9), L. ivanovii (1) e L. seeligeri (1). L. monocytogenes foi isolada apenas de amostras coletadas de carcaça após a evisceração e do ambiente da câmara fria em um dos matadouros frigoríficos. Os isolados de $L$. monocytogenes foram classificados em três sorotipos (1/2a, 1/2b e 1/2c) e dois pulsotipos. A combinação dos sorotipos e pulsotipos resultaram na formação de quatro perfis clonais (I-IV). A identificação de um perfil clonal (I) comum em cinco carcaças amostradas após a etapa de evisceração demonstra que esta etapa é critica para contaminação cruzada durante o processo de abate.
\end{abstract}

Palavras-chave: abate de suínos; PFGE; Listeria

\section{DISTRIBUTION OF LISTERIA MONOCYTOGENES CLONAL GROUPS ON CARCASSES AND ENVIRONMENT OF SWINE SLAUGHTERHOUSES}

\begin{abstract}
The aim of this study was to evaluate the isolation and distribution of Listeria monocytogenes clonal groups originated from serotyping and pulsed-field gel eletrophoresis (PFGE) analysis of isolates from environment and from pork carcasses sampled at four different points of the slaughter line. Swabs were taken from the environment $(n=30)$ and from the surface of carcasses $(n=240)$ after scalding, flaming, evisceration and before cooling in two slaughterhouses of Southern Brazil. From 270 performed swabs, $21(7.7 \%)$ were positive for Listeria spp., identified as follow: $L$. innocua (10), L. monocytogenes (9), L. ivanovii (1) e L. seeligeri (1). L. monocytogenes was isolated from carcass samples taken after evisceration and before cooling. L. monocytogenes strains were classified in three serotypes (1/2a, 1/2b and 1/2c) and two pulsotypes. The association of serotypes and pulsotypes originated four clonal groups (I-IV) among L. monocytogenes strains. The identification of a single clonal group (I) of $L$. monocytogenes in five carcasses after the evisceration demonstrates that this is a critical step for cross-contaminating during the slaughter process.
\end{abstract}

Key Words: pig slaughter; PFGE; Listeria 


\section{INTRODUÇÃO}

A listeriose em humanos, apesar de apresentar menor incidência em comparação com outras doenças veiculadas por alimentos, tem sido responsável por até um terço dos óbitos em decorrência desse grupo de enfermidades (EFSA, 2007). Os casos mais graves predominam em crianças, idosos e indivíduos imunocomprometidos; em gestantes a infecção pode ocasionar aborto ou parto prematuro (Swaminathan e GernerSmidt, 2007). Os casos de listeriose em humanos são causados quase que exclusivamente por Listeria monocytogenes, portanto essa espécie tem sido 0 foco dos critérios microbiológicos em legislações concernentes à inocuidade dos alimentos. O parâmetro ausência de $L$. monocytogenes tem sido adotado, de acordo com o país, para alimentos de pronto consumo em geral, ou apenas para aqueles que serão consumidos por grupo de risco, ou que propiciam a multiplicação da bactéria (Yang et al., 2006; EFSA, 2007).

No Brasil, segundo a Agência Nacional de Vigilância Sanitária (Brasil, 2001), o critério em relação a $L$. monocytogenes prevê a ausência em 25 $\mathrm{g}$ apenas em queijos de média e alta umidade $(\geq 36 \%)$. Porém, em 2009, o Ministério da Agricultura, Pecuária e Abastecimento editou a Instrução Normativa (IN) $n^{\circ} 9 \mathrm{com}$ vistas a instituir o controle desse micro-organismo em estabelecimentos que elaboram produtos de origem animal prontos para o consumo com alta atividade de água e baixa acidez (Brasil, 2009). Além da coleta de amostras de produto para a pesquisa microbiológica, a IN9 estabelece a inspeção dos processos de produção, inclusive a avaliação da matéria-prima.

L. monocytogenes apresenta uma série de características que favorecem sua permanência no alimento e no ambiente de processamento, tal como a sobrevivência em alimentos ácidos e com alto teor de sal, a capacidade de multiplicação em temperatura de refrigeração e a habilidade de formar biofilmes (Swaminathan e Gerner-Smidt, 2007). Em virtude da ampla distribuição e sobrevivência no ambiente, o monitoramento e controle são necessários em todas as etapas da elaboração de produtos e, no caso dos cárneos, iniciando pela etapa de abate dos animais. Estudos que investigaram a ocorrência de L. monocytogenes em produtos de origem suína encontraram freqüências que variaram de $28,7 \%$ em carne fresca coletada no comércio até $71,6 \%$ de amostras de carne moída para elaboração de linguiça (Thévenot et al., 2005; Ochiai et al., 2010). Por meio da técnica de macro-restrição de DNA, a contaminação da carne suína pode ser relacionada tanto a isolados de L. monocytogenes persistentes no ambiente de plantas de processamento quanto á cepas presentes no conteúdo intestinal e tonsilas dos animais abatidos (Chasseignaux et al., 2001; Thévenot et al., 2005; Sanna et al., 2010).

No Brasil, existem relatos sobre o isolamento de L. monocytogenes a partir de diversos produtos cárneos como salame (Sakate et al., 2003), linguiça frescal (Silva et al., 2004), presunto (Fai et al., 2011) e frango (Nalério et al., 2009), porém estudos conduzidos em matadouros frigoríficos de suínos ainda são escassos (Santos et al., 2005). A partir disso, o objetivo do estudo foi investigar a presença e distribuição de isolados de $L$. monocytogenes em carcaças de suínos em quatro etapas da linha de abate (após escaldagem, após chamuscamento, após evisceração e antes da entrada na câmara fria) e no ambiente de matadouros frigoríficos. 

matadouros frigoríficos de suínos

\section{MATERIAL E MÉTODOS}

Em dois matadouros frigoríficos (A e B) sob Inspeção Federal, um localizado no Estado do Rio Grande do Sul e outro em Santa Catarina, foi conduzido um estudo longitudinal, no qual uma mesma carcaça foi amostrada, por meio de suabe de superfície, em quatro etapas da linha de abate. No início do primeiro turno de abate, a primeira carcaça foi identificada e amostrada nas seguintes etapas: após escaldagem, após chamuscamento, após evisceração e antes da entrada na câmara fria. Em intervalos de vinte minutos, outra carcaça foi identificada e submetida à coleta de amostra nas mesmas etapas, de forma a amostrar carcaças processadas no decorrer de todo o turno de abate (aproximadamente quatro horas). Em cada coleta realizada nos frigoríficos, foram amostradas 12 carcaças, totalizando 48 suabes de superfície. $O$ estabelecimento $A$ foi amostrado duas vezes, entre os meses de março e junho de 2008. No estabelecimento $B$, além das duas amostragens realizadas nesse período, foi conduzida uma terceira coleta de amostras, em junho de 2009.

Em cada uma das etapas amostradas, uma esponja estéril (5x7 $\mathrm{cm})$ confeccionada com tecido de celulose, foi friccionada numa área de $300 \mathrm{~cm}^{2}$, delimitada por um molde de cartolina estéril $(15 \times 20 \mathrm{~cm}), \quad$ na superfície externa da paleta da carcaça identificada. Um total de 24 carcaças (96 suabes) e 36 carcaças (144 suabes) foram analisadas, respectivamente, nos estabelecimentos $\mathrm{A}$ e $\mathrm{B}$.

Paralelamente, em cada coleta, um total de seis amostras ambientais foram coletadas, por meio de uma esponja individual friccionada numa área de $300 \mathrm{~cm}^{2}$ de cada um dos seguintes locais: piso da pocilga de espera $(n=2)$, no piso e na parede da sala de abate próximo à área de evisceração $(n=2)$ e da câmara fria $(n=2)$, seguindo o mesmo procedimento acima descrito. Um total de 12 e 18 amostras ambientais foram analisadas nos Frigoríficos A e B, respectivamente.

Após a coleta da amostra, as esponjas foram acondicionadas, individualmente, em sacos plásticos contendo $25 \mathrm{~mL}$ de água peptonada $0,1 \%$ e transportadas até o laboratório em caixas isotérmicas. As amostras coletadas foram analisadas em até 24 horas. O isolamento de Listeria spp. foi realizado conforme a Instrução Normativa 62 (IN62) (Brasil, 2003), a qual prevê o enriquecimento da amostra em Caldo de Enriquecimento Modificado para Listeria (UVM, AES Laboratory, $30^{\circ} \mathrm{C}, 24 \mathrm{~h}$ ), seguida de incubação em Caldo Fraser (BD Diagnostic, $35^{\circ} \mathrm{C}, 24 \mathrm{~h}$ ) $\mathrm{e}$ isolamento em Agar seletivo PALCAM (BD Diagnostic), sob condição de microaerofilia $\quad\left(37^{\circ} \mathrm{C}, \quad 48 \mathrm{~h}\right)$. Paralelamente, uma alíquota de cada amostra foi semeada, diretamente, em Agar Listeria segundo Ottaviani e Agosti (ALOA, AES Laboratory) e incubada á $37^{\circ} \mathrm{C}$, por 48 horas. Colônias típicas no Agar PALCAM (colônias esféricas, pretas, rodeadas por halo preto de hidrólise da esculina) e no Agar ALOA (colônias verde-azuladas, rodeadas ou não por halo opaco) foram submetidas à confirmação bioquímica, conforme descrito na IN62. Como controle em todas as etapas foi empregada a cepa L. monocytogenes ATCC 7644. Após a confirmação por testes bioquímicos, indicados na IN62, os isolados identificados como $L$. monocytogenes foram encaminhados ao Laboratório de Zoonoses Bacterianas da Fundação Instituto Oswaldo Cruz para sorotipificação.

Os isolados de $L$. monocytogenes foram submetidos à genotipificação por meio de macro-restrição de DNA seguida de eletroforese em campo pulsado (PFGE). A preparação e a clivagem do DNA total foram conduzidas 
como descrito (Pulsenet, 2009). As amostras foram analisadas após clivagem com as enzimas Apal (20 unidades) e Ascl (20 unidades) (New England BioLabs). Os produtos da clivagem foram separados em gel de agarose $1 \%$ (Pulsed Field Agarose, BioRad) em tampão TBE 0,5X (0,9M Tris base, 0,9 $\mathrm{M}$ ácido bórico, 0,02 $\mathrm{M}$ EDTA, pH 8,0), por um período de 19 horas $\left(6 \mathrm{~V} / \mathrm{cm}^{-1}\right)$, em equipamento de eletroforese de campo pulsado (CHEFDRII, BioRad). O tempo de pulso inicial foi de 4 segundos e o tempo final de 40 segundos. A cepa padrão de Salmonella Braenderup (ATCC BAA-664), clivada com a enzima Xbal (Fermentas), serviu como referência de tamanho dos fragmentos gerados. Após a corrida, o gel foi corado em solução de brometo de etídio $(10 \mathrm{mg} / \mathrm{mL})$ diluída $(1: 10.000)$ em água destilada, e visualizado em transiluminador. As imagens foram capturadas e digitalizadas pelo sistema Kodak 2200 (Rochester, New York, USA). O perfil de macro-restrição foi analisado visualmente e cada posição de banda foi determinada por comparação com a cepa referência. Isolados com uma banda de diferença foram considerados como sendo de pulsotipos diferentes.

\section{RESULTADOS E DISCUSSÃO}

Do total de 270 suabes coletados de carcaça $(n=240)$ e ambiente $(n=30)$, em $21(7,7 \%)$ houve isolamento de Listeria spp., distribuído da seguinte forma: $L$. innocua $(10 ; 47,6 \%), \quad L$. monocytogenes $(9 ; 42,8 \%)$, L. ivanovii (1; $4,8 \%)$ e L. seeligeri $(1 ; 4,8 \%)$.

A frequência de isolamento de Listeria spp. diferiu entre os matadouros-frigoríficos e entre os dias de abate. No estabelecimento A, obteve-se apenas uma amostra positiva (1/96) do total de suabes de carcaça analisados. Dessa amostra, coletada após a escaldagem, houve $\mathrm{o}$ isolamento de L. inoccua. Todas as amostras, coletadas no ambiente do matadourofrigorífico $A$, resultaram negativas. No estabelecimento B, $12(33,3 \%)$ do total de 36 carcaças foram positivas para Listeria spp. em uma ou mais amostras coletadas ao longo da linha de abate, totalizando $11,1 \%$ de suabes positivos (16/144) (Tabela 1). A partir das amostras ambientais do estabelecimento $B$, foi isolada $L$. seeligeri do piso da câmara fria na primeira coleta, dois suabes de câmara fria (piso e parede) foram positivos para L. monocytogenes na segunda coleta, e L. innocua foi encontrada no piso próximo à área de evisceração na terceira coleta.

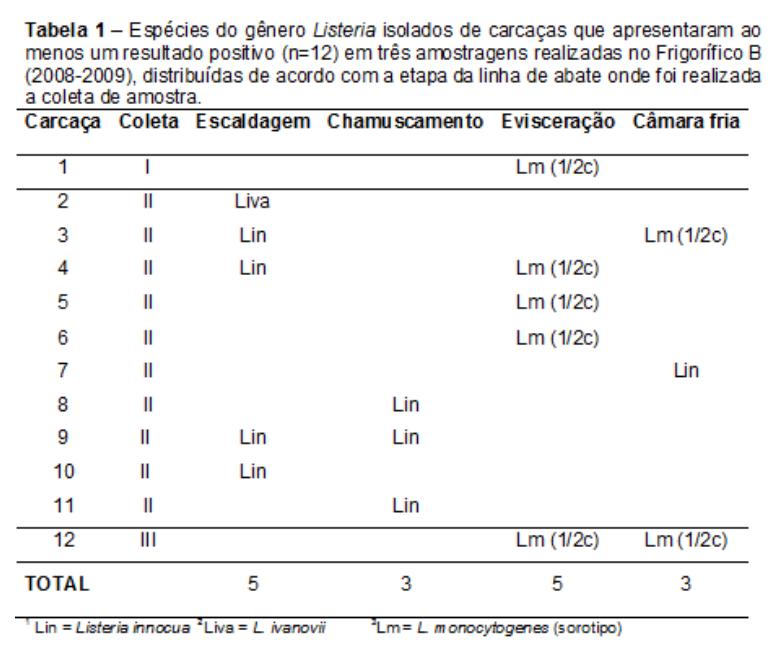

Os nove isolados de $L$. monocytogenes foram classificados em três sorotipos: os sete isolados de carcaça foram identificados como sorotipo $1 / 2 \mathrm{c}$, enquanto os dois isolados ambientais pertenciam aos sorotipos 1/2a e 1/2b. Esses sorotipos têm sido os mais frequentemente encontrados em produtos cárneos e no ambiente de plantas de abate (Thévenot et al., 2006; Swaminathan \& Gerner-Smidt, 2007; Gianfranceschi et al., 2009; Ochi et al., 2010). No Brasil, Von Laer et al. (2009) encontraram, em uma planta de produção de linguiça frescal, 71 isolados de L. monocytogenes, sendo $59(71,1 \%)$ do sorotipo 1/2c, $10(12,1 \%)$ do sorotipo 

matadouros frigoríficos de suínos

$1 / 2 b$ e $2(2,4 \%)$ do sorotipo $4 b$. Nesse estudo, o sorotipo $1 / 2 \mathrm{c}$ foi isolado em todos os pontos de amostragem, com exceção do produto final, demonstrando a ampla distribuição de $L$. monocytogenes durante a elaboração de linguiça frescal.

Dentre os sorotipos identificados em nosso estudo, os sorotipos $1 / 2 a$ e $1 / 2 b$, encontrados no ambiente da câmara fria, têm sido relacionados com casos de listeriose em humanos e, juntamente com 0 sorotipo $4 b$ são responsáveis por 95\% dos casos relatados mundialmente (Gianfranceschi et al., 2009; Clark et al., 2010). Por outro lado, o sorotipo $1 / 2 \mathrm{c}$, único encontrado em carcaças em nosso estudo, aparece esporadicamente em casos de listeriose humana. Na Itália, Gianfranceschi et al. (2009), no total de 57 isolados de $L$. monocytogenes proveniente de humanos, encontraram apenas quatro do sorotipo $1 / 2 \mathrm{c}$, ao passo que os sorotipos $1 / 2 a$ e $4 b$ foram os predominantes. A mesma situação foi relatada no Canadá, onde, entre 756 isolados de humanos, apenas 8 pertenciam ao sorotipo $1 / 2 \mathrm{c}$, enquanto 589 isolados estavam distribuídos homogeneamente entre os sorotipos 1/2a e 4b (Clark et al., 2010). Entretanto, pelos critérios adotados em relação à inocuidade dos alimentos, a ocorrência de isolado de $L$. monocytogenes, independentemente do sorotipo, representa risco (Thévenot et al., 2006) e demanda o estabelecimento de medidas de controle.

A clivagem dos isolados de $L$. monocytogenes, com as enzimas Apal e Ascl, gerou de oito a treze fragmentos, variando entre 1.135 e 33,3 Kb (Figura 1). De acordo com os perfis apresentados, os isolados foram agrupados em dois pulsotipos distintos (Ap1/As1 e Ap2/As2). Associando os pulsotipos com 0 resultado de sorotipificação, foi identificado um grupo clonal, que incluiu todos os isolados de carcaças amostradas na primeira e na segunda coleta realizada no frigorífico $B$ (Tabela 2). Os dois isolados de ambiente e o isolado de carcaça da terceira coleta no frigorífico $B$ apareceram como clones distintos entre si, e não pertenciam ao grupo clonal identificado.

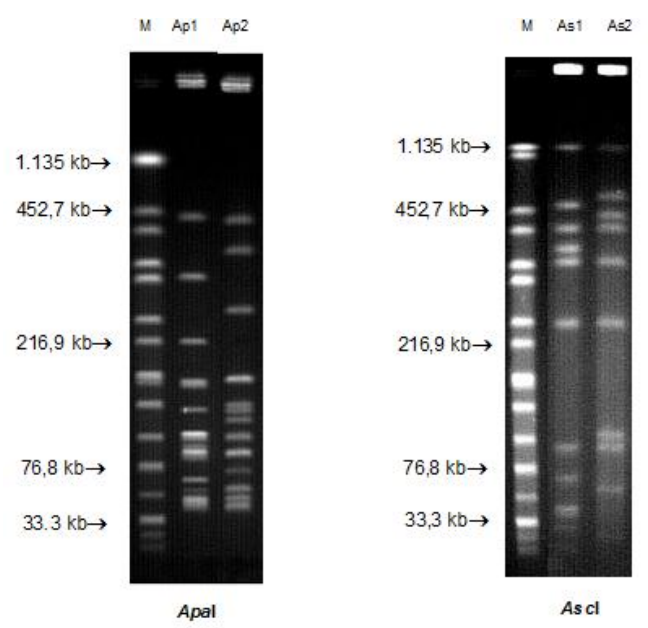

Figura 1 - Perfis de macro-restrição de isolados de Listeria monocytogenes, provenientes de matadouro frigorífico de suínos clivados com enzima Apal e Ascl. M, marcador de peso molecular Salmonella Braenderup clivada com Xbal.

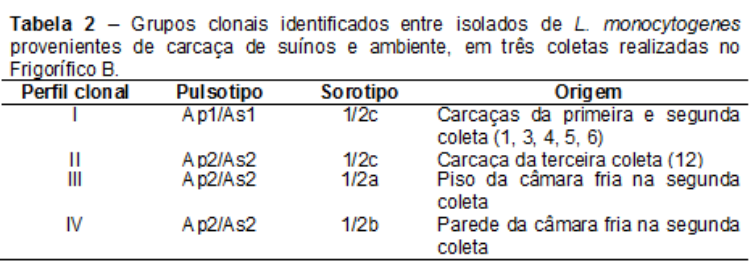

A técnica de PFGE tem sido empregada, isolada ou associada a outros critérios de tipificação, para identificar grupos clonais de $L$. monocytogenes envolvidos em surtos e discriminar a origem da contaminação de produtos (Lópes et al., 2008; Von Laer et al., 2009; Clark et al., 2010). A caracterização, realizada em nosso estudo por meio de sorotipificação e determinação de pulsotipos, evidenciou que cinco isolados obtidos de carcaças pertenciam a um grupo clonal (I), estando presentes em carcaças originadas de um mesmo turno de abate ou de carcaças processadas em dias distintos. 
As origens sugeridas para a contaminação de carcaças suínas por $L$. monocytogenes têm sido o ambiente dos matadouros-frigoríficos ou os próprios animais abatidos (Chasseignaux et al., 2001; Thévenot et al., 2006; Von Laer et al., 2009). Em nosso estudo, a origem ambiental da contaminação das carcaças não pode ser evidenciada, pois os isolados de $L$. monocytogenes de ambiente e de carcaça não pertenciam ao mesmo grupo clonal. Portanto, a origem dos isolados identificado em cinco carcaças foi, provavelmente, o conteúdo intestinal ou as tonsilas dos animais abatidos. Suínos podem carrear Listeria spp. no trato gastrintestinal, como pode ser evidenciado em estudos que amostraram fezes e suabes peri-anais de animais ao abate (Beloeil et al., 2003). Santos et al. (2005) encontraram $L$. monocytogenes na superfície de carcaças suínas apenas após as etapas de evisceração e após resfriamento, e sugeriram o conteúdo intestinal como provável fonte de contaminação. Porém, outros estudos (Fredriksoson-Ahoma, Gerhardt e Stollte, 2009; Hellström et al., 2010) demonstraram que as tonsilas albergam populações de $L$. monocytogenes com frequência elevada, tornando o contato de tonsilas e língua com o restante da carcaça durante a retirada das vísceras e da cabeça a mais importante via de sua contaminação (Thévenot et al., 2006; Hellström et al., 2010). Ambas as hipóteses são compatíveis com o resultado obtido no presente estudo, onde os isolados de $L$. monocytogenes foram identificados apenas em suabes colhidos após a evisceração e no prérefriamento. Da mesma forma, é provável que esse grupo clonal entre repetidas vezes na linha de abate, uma vez que nesse grupo existiam isolados encontrados em carcaças da primeira e na segunda coleta. Existem diversas origens possíveis para o grupo clonal encontrado nas carcaças após o processo de evisceração: $i$. os animais podem ter sido infectados nas granjas de origem ou durante o transporte e permanência nas pocilgas pré-abate, albergando a bactéria no seu trato intestinal ou tonsilas; ii. ocorreu a contaminação cruzada entre carcaças, por meio de utensílios, durante a evisceração. Em ambos os casos, a implantação de boas práticas de fabricação que incluam a adequada desinfecção de utensílios, a oclusão do reto impedindo a saída de conteúdo do intestino e a remoção de vísceras de forma que não ocorra a sua ruptura ou contato das tonsilas e língua com a carcaça, podem contribuir para diminuir a disseminação de $L$. monocytogenes durante o abate de suínos.

\section{CONCLUSÃO}

Listeria monocytogenes pode ser encontrada no ambiente de matadourosfrigoríficos, bem como contaminando a superfície de carcaças suínas em linhas de abate. A identificação de um grupo clonal único de L. monocytogenes em carcaças apenas após a etapa de evisceração indica que essa etapa é crítica para a contaminação cruzada durante o abate de suínos e deve ser prioritária nos programas de boas práticas de fabricação dos matadouros frigoríficos.

\section{AGRADECIMENTOS}

Os autores agradecem a Vanessa Dias pelo auxílio técnico e ao Dr. Ernesto Hoffer pela sorotipificação dos isolados de L. monocytogenes.

\section{REFERÊNCIAS}

BELOEIL, P.A.; CHAUVIN C.; TOQUIN M.-T. et al. Listeria monocytogenes contamination of finishing pigs: an exploratory epidemiological survey in France. Veterinary Reserch, v.34, n.6, p.737-748, 2003. 

matadouros frigoríficos de suínos

BRASIL. Agência Nacional de Vigilância Sanitária. Legislação Resolução - RDC nำ12. Regulamento técnico sobre padrões microbiológicos para alimentos. Diário Oficial da União. Brasília, DF, 02 de janeiro de 2001.

BRASIL. Ministério da Agricultura, Pecuária e Abastecimento. Instrução Normativa $n^{\circ} 9$. Institui os procedimentos de controle de Listeria monocytogenes em produtos de origem animal prontos para consumo. Diário Oficial da União. Brasília, DF, 08 de abril de 2009.

BRASIL. Ministério da Saúde. Instrução Normativa nํ 62 de 26/08/2003. Métodos analíticos oficiais para análises microbiológicas para controle de produtos de origem animal e água. Diário Oficial da União. Brasília, DF, p.14, 2003.

CLARK, C.G.; FARBER, J.; PAGOTTO, F. et al. Surveillance for Listeria monocytogenes and listeriosis, 1995-2004. Epidemiology and Infection, v.138, n.4 p.559-572, 2010.

CHASSEIGNAUX, E.; TOQUIN, M.-T.; RAGIMBEAU, C. et al. Molecular epidemiology of Listeria monocytogenes isolates collected from the environment, raw meat and raw products in two poultry and pork-processing plants. Journal of Applied Microbiology, v. 91, n.5, p.888-899, 2001.

EUROPEAN FOOD SAFETY AUTHORITYEFSA. The Community Summary Report on Trends and Sources of Zoonoses, Zoonotic Agents, Antimicrobial Resistance and Foodborne Outbreaks in the European Union in 2006. The EFSA Journal, v.130, p.3-352, 2007.

FAI, A.E.C.; FIGUEIREDO, E.A.T.; VERDIN, S.E.F. et al. Salmonella sp. e Listeria monocytogenes em presunto suíno comercializado em supermercados de Fortaleza (CE, Brasil): fator de risco para saúde pública. Ciência \& Saúde coletiva, v.16, n.2, p.657-662, 2011.

FREDRIKSOSON-AHOMA, M.; GERHARDT, M.; STOLLTE, A. High bacterial contamination of pig tonsils at slaughter. Meat Science, v.83, n.2, p.336-336, 2009.

GIANFRANCESCHI, M.V.; D'OTTAVIO, M.C.; GATTUSO, A. et al. Distribution of serotypes and pulsotypes of Listeria monocytogenes from human, food and environmental isolates (Italy
2002-2005). Food Microbiology, v.26, n.5, p.520-526, 2009.

LÓPES, V.; VILLATORO, D.; ORTIZ, S. et al. Molecular tracking of Listeria monocytogenes in an Iberian pig abattoir and processing plant. Meat Science, v.78, n.1-2, p.130-134, 2008.

NALÉRIO, E.S.; ARAÚJO, M.R.; MENDONÇA, K.S. et al. Listeria monocytogenes: monitoramento desse perigo biológico na cadeia produtiva de frangos do sul do Rio Grande do Sul. Ciência e Tecnologia de Alimentos, v.29, n.3, p.626-630, 2009.

OCHIAI, Y.; YAMADA, F.; BATMUNKH, O. et al. Prevalence of Listeria monocytogenes in retailed meat in the Tokyo metropolitan area. Journal of Food Protection, v.73, n.9, p.1688-1693, 2010.

PULSENET. [2009]. The National Molecular Subtyping Network for Foodborne Disease Surveillance. Standardized Laboratory Protocol for Molecular Subtyping of Listeria monocytogenes by Pulsed Field Gel Electrophoresis (PFGE). Disponível em:<http://www.cdc.gov/pulsenet>. Acesso em: 05/05/2009.

SAKATE, I.; ARAGON, L.C.; RAGHIANTE, F. et al. Quantificação de Listeria monocytogenes em salames fatiados embalados á vácuo. Archivos Latinoamericanos de Nutricion, v.53, n.2, p.184-187, 2003.

SANNA, H.; RIIKKA, L.; SIEKKINEN, K.-M. et al. Listeria monocytogenes contamination in pork can originate from farms. Journal of Food Protection, v.73, n.4, p.641-648, 2010.

SANTOS, L.A.; GUIMARÃES, L.A.; ARRUDA, P.S. et al. Detecção de Listeria monocytogenes como subsídio à determinação de pontos críticos de controle no abate de suínos.

Bioscience Journal, v.21, n.2, p.131-135, 2005.

SILVA, W.P.; LIMA, A.S.; GANDRA, E.A. et al. Listeria spp. no processamento de lingüiça frescal em frigoríficos de Pelotas, RS, Brasil. Ciência Rural, v.34, n.3, p.911-916, 2004.

SWAMINATHAN, B.; GERNER-SMIDT, P. The epidemiology of human listeriosis. Microbes Infection, v.9, n.10, p.1236-1243, 2007.

THÉVENOT, D.; DELIGNETTE-MULLER, M.L.; CHRISTIEANS, S. et al. Prevalence of Listeria monocytogenes in 13 dried sausage processing plants and their products. International Journal 
of Food Microbiology, v.102, n.1, p.85-94, 2005.

THÉVENOT, D.; DERNBURG, A.; VERNOZY-

ROZAND, C. et al. An updated review of Listeria monocytogenes in the pork meat industry and its products. Journal of Applied Microbiology, v.101, n.1, p.7-17, 2006.

VON LAER, A.E.; LIMA, A.S.; TRINDADE, P.S. et al. Characterization of Listeria monocytogenes isolated from a fresh mixed sausage processing line in Pelotas-RS by PFGE. Brazilian Journal of Microbiology, v.40, n.3, p.574-582, 2009.

YANG, H.; AMIRHOSSEIN, M.; JAYKUS, L.-A. et al. Consumer- phase risk assessment for Listeria monocytogenes in deli meats. Risk Analysis, v. 26, n.1, p.89-109, 2006. 